\title{
Arterite de Takayasu: aspectos clínicos e terapêuticos em 36 pacientes
}

\author{
Takayasu's arteritis: clinical and therapeutic aspects in 36 patients
}

\begin{abstract}
Marília Duarte Brandão Panico1, Ethel Stambovsky Spichler ${ }^{2}$, Leandro Cordeiro Dias Rodrigues ${ }^{3}$, Fernando Oliveira ${ }^{3}$, Daniel Buchatsky ${ }^{4}$, Carmen Porto ${ }^{5}$, Márcia Ribeiro Alves ${ }^{5}$, David Spichler ${ }^{6}$
\end{abstract}

\section{Resumo}

Contexto: A arterite de Takayasu é uma vasculite crônica, geralmente com diagnóstico tardio devido à pouca especificidade dos sintomas durante a fase inicial do acometimento vascular. A terapêutica de eleição é o uso de imunossupressores. O procedimento cirúrgico, quando necessário, é sempre evitado na fase aguda.

Objetivo: Descrever alterações clínicas, laboratoriais e vasculares de arterite de Takayasu no período de 1977 a 2006.

Método: A amostra compreendeu 36 pacientes -10 brancos, 35 mulheres, idade média de 31,7 anos $( \pm 13,7)$, com prevalência significante na quarta década $(\mathrm{p}<0,005)$. Evolução de 3 anos e período até o diagnóstico de 7,9 anos. Velocidade de hemossedimentação (VHS) e proteína $\mathrm{C}$ reativa (PCR) avaliaram atividade da doença, e o duplex scan aferiu a espessura médio- intimal da artéria carótida.

Resultados: Hipertensão arterial sistêmica e claudicação de membros superiores e inferiores foram ressaltados em 85,2, 69,5 e $30,5 \%$, respectivamente. O resultado da VHS foi $>60 \mathrm{~mm}$ em $50 \%$ da amostra $(\mathrm{p}<0,005)$. PCR $\mathrm{mg} / \mathrm{dL}$ foi realizado em 18 , variando de 0,4-25 na admissão para 0,11-1,9 na evolução. Doença auto-imune, tuberculose e HIV correlacionaram-se em 19,4, 8,3 e 2,7\%, respectivamente. Lesões aórticas foram significativas em $22 \%$ (quatro oclusões, dois aneurismas infra-renais, um torácico). Em 19,4\%, foram acometidas artérias renais e subclávias uma oclusão bilateral de carótidas, e em $25 \%$ os membros inferiores. A espessura médio-intimal da carótida comum foi estratificada em: $\geq 3 \mathrm{~mm},<3 \mathrm{e} \geq 1,7,<1,7 \mathrm{e} \geq$ 1,2 e $<1,2 \mathrm{~mm}$, representando $41,6,19,4,8,37$ e $30,50 \%$, respectivamente $(\mathrm{p}<0,005)$. Glicocorticóides foram utilizados em $61,1 \%$, azatioprina em $16.6 \%$, e associada a ciclofosfamida em $8,3 \%$. Procedimento cirúrgico ou endovascular foi realizado em $30,5 \% \mathrm{com}$ dois óbitos por complicações cardiovasculares.

Conclusões: A VHS, PCR, e a espessura médio-intimal nas carótidas são importantes marcadores de acompanhamento da arterite de Takayasu. O período entre os sintomas e o diagnóstico deve ser abreviado, com redução da morbimortalidade.

Palavras-chave: Arterite de Takayasu, diagnóstico por imagem, imagem por duplex scan, carótida, aorta, espessamento intimal, tratamento clínico, tratamento cirúrgico.

\begin{abstract}
Background: Takayasu arteritis is a chronic vasculitis often with delayed diagnosis due to the nonspecific presentation of clinical symptoms in its initial phase. Treatment includes imunosuppression drugs. Surgical treatment, when necessary, should be avoided in the acute phase.
\end{abstract}

Objective: To describe clinical, laboratory and vascular findings in Takayasu's arteritis from 1977 through 2006.

Methods: The sample was comprised of 36 patients (10 Caucasians, 35 women), mean age of $31.7( \pm 13.7)$ years, and significant prevalence in the forth decade $(\mathrm{p}<0.005)$. Disease course was 3 years and time until diagnosis was 7.9 years. Erythrocyte sedimentation rate (ESR) and $\mathrm{C}$-reactive protein (CRP) were used to assess disease activity, and duplex scan to measure carotid artery intima-media wall thickness.

Results: Hypertension was present in $85.2 \%$, and upper and lower limb claudication in 69.5 and $30.5 \%$, respectively. ESR was $>60 \mathrm{~mm}$ in $50 \%$ of the sample $(\mathrm{p}<0.005)$. PCR $\mathrm{mg} / \mathrm{dL}$ was performed in 18 cases, ranging from 0.4-25 on admission to 0.11-1.9 during disease course. Autoimmune diseases, tuberculosis and HIV correlated in 19.4, 8.3 and $2.7 \%$, respectively. Major aortic lesions were detected in $22.2 \%$ (four occlusions, two infrarenal aneurysms, one thoracic aneurysm). Other arteries involved renal, subclavian and one carotid occlusion $(19 \%)$, and some level of lower limb occlusion $(25 \%)$. Intima-media thickness was stratified in $\geq 3 \mathrm{~mm}(41.6 \%),<3$ and $\geq 1.7(19.4 \%),<$ 1.7 and $\geq 1.2(8.37 \%)$, and $<1.2 \mathrm{~mm}(30.50 \%)(\mathrm{p}<0.005)$. Glucocorticoids were used in $61 \%$, azathioprine in $16.6 \%$, and azathioprine combined with cyclophosphamide in $8.3 \%$. Surgical and endovascular procedures were performed in $30.5 \%$. Two patients died due to cardiovascular diseases.

Conclusions: Carotid intima-media thickness, PCR, and ESR are important markers for the follow-up of Takayasu's arteritis. Delay in diagnosis is an important issue for Takayasu's progression, since it may reduce morbidity and mortality rates.

Keywords: Takayasu's arteritis, imaging diagnosis, duplex scan imaging, carotid, aorta, intimal thickening clinical treatment, surgical treatment.

1. Chefe, Disciplina de Angiologia, Faculdade de Ciências Médicas, Hospital Universitário Pedro Ernesto (HUPE), Universidade Estado do Rio de Janeiro (UERJ), Rio de Janeiro, RJ.

2. Professora titular visitante, Faculdade de Ciências Médicas, HUPE, UERJ, Rio de Janeiro, RJ.

3. Acadêmico de Medicina, Faculdade de Ciências Médicas, HUPE, UERJ, Rio de Janeiro, RJ.

4. Pós-graduando, Especialização em Angiologia, Faculdade de Ciências Médicas, HUPE, UERJ, Rio de Janeiro, RJ.

5. Professora assistente, Disciplina de Angiologia, Faculdade de Ciências Médicas, HUPE, UERJ, Rio de Janeiro, RJ.

6. Livre-docente, Cirurgia Vascular, Universidade Federal do Estado do Rio de Janeiro (UNIRIO), Rio de Janeiro, RJ.

Não foram declarados conflitos de interesse associados à publicação deste artigo.

Artigo submetido em 09.03.08, aceito em 15.04.08. 


\section{Introdução}

A arterite de Takayasu (AT) é uma doença inflamatória crônica progressiva caracterizada como vasculite granulomatosa crônica, que envolve a aorta e seus principais ramos ${ }^{1-6}$. Ocorre inflamação granulomatosa transmural, podendo causar estenose, oclusão, dilatação e/ou formação de aneurismas nas artérias envolvidas. Seu diagnóstico persiste como um grande desafio diante das evidências clínicas e laboratoriais inespecíficas ${ }^{1-7}$.

Critérios diagnósticos baseados em alterações da parede arterial, através da determinação do grau de espessamento da parede, podem ser avaliados e acompanhados pelo duplex $\operatorname{scan}^{8}$, angiografia ${ }^{9}$, tomografia computadorizada $(\mathrm{TC})^{9}$ e angiorressonância magnética (angio-RM) ${ }^{10,11}$. Estudos recentes mostraram que angio$\mathrm{RM}^{11}$, TC e angiografia são muito específicas para o detalhamento das lesões na parede da aorta e de seus ramos. O acompanhamento pelo duplex $\operatorname{scan}^{8}$ na avaliação da espessura do complexo médio-intimal da carótida comum, correlacionando-a com os aspectos clínico-laboratoriais e a evolução da AT, pode ser utilizado.

Inúmeras doenças apresentam como diagnóstico diferencial a AT, tais como síndrome de Marfan, EhlersDanlos, displasia fibromuscular, entre outras vasculites $^{12-17}$. Apresenta maior incidência no Japão ${ }^{16}$, China $^{17}$, Índia ${ }^{18}$ e México ${ }^{19}$.

A incidência relatada é de 1,2, 2,6 e 2,9/milhão/ano nos $\mathrm{EUA}^{20}$, na Europa ${ }^{14}$ e no México ${ }^{6,15}$, respectivamente. A incidência na Ásia é 100 vezes maior ${ }^{13,19,20}$. Em 1990, foi incluída na lista de doenças de difícil terapêutica mantida pelo governo japonês ${ }^{20}$, e até o ano de 2002, 5.000 pacientes tinham sido registrados. Ressalta-se que a AT tem incidência de 90\% em mulheres entre os 18 e 40 anos $^{5}$.

\section{Etiologia, etiopatogenia e manifestações clínicas}

O mecanismo etiológico permanece desconhecido. Chauhan et al. $^{21}$ relataram que auto-anticorpos (AAECA) atuam contra a proteína heat-shock com aumento da expressão de E-selectina e da molécula de adesão à célula vascular-1, bem como aumento da produção de IL-4, IL-6 e IL-8. Referiram indução de apoptose no endotélio aórtico, sugerindo que o os AAECA podem causar disfunção vascular ${ }^{21}$.
Verma et al. ${ }^{22}$ referiram níveis plasmáticos de IL-12 aumentados significativamente na AT. Tripathy et al. ${ }^{23}$ estudaram os níveis de citosinas nas células linfocitárias tipo $\mathrm{T}$ (células $\mathrm{T}$ ), reportando percentagens aumentadas de fator de necrose tumoral $\alpha$ (TNF- $\alpha$ ) e diminuídas de IL-2, produzidas pelas células T na fase aguda da AT. Numano \& Kobayashi ${ }^{24}$ mostram incidência de carreadores de HLA B 52 antígeno na população japonesa, apresentando risco mais elevado de desenvolver AT.

A AT se insere no conjunto das vasculites primárias sistêmicas, caracterizadas por inflamação e necrose fibrinóide $^{25}$. A clínica é variável, dependente da localização e extensão dos vasos acometidos, do processo inflamatório e efeitos sistêmicos desencadeados ${ }^{16}$, com uma evolução trifásica da doença ${ }^{13,19}$.

A primeira fase ressalta o período inflamatório, com presença de pulsos e sintomas inespecíficos, como febre, artralgia, mialgia, sudorese noturna, anorexia, cefaléia, tontura, mal-estar, eritema nodoso, astenia e emagrecimento. Neste momento, inicia-se uma migração de células inflamatórias através dos vasa vasorum até a camada média $\operatorname{arterial}^{13,19}$.

A segunda fase exacerba inflamação vascular, com dor no trajeto do vaso (carotidínia). O processo inflamatório torna-se intenso e concentrado na camada média, com destruição das fibras colágenas e migração celular para a adventícia, e a lesão endotelial inicia o processo da estenose, oclusão e dilatação ${ }^{13,19}$.

A última fase é fibrótica, com estenose, oclusão ou dilatação aneurismática. Ocorrem alterações isquêmicas secundárias às oclusões arteriais, alterações dos pulsos arteriais periféricos mais freqüentes (ausência, diminuição de amplitude ou diferença na pressão arterial em relação ao membro heterólogo de $30 \mathrm{mmHg}$ ), sopro e frêmito em trajetos arteriais, carótidas sensíveis, parestesias e claudicação, principalmente em membros superiores (MS) $)^{13,19}$.

A hipertensão por estenose da artéria renal na AT é a causa mais comum de hipertensão secundária relatada na Ásia ${ }^{19}$. Ocorre ainda regurgitação mitral ou aórtica, cardiomiopatia dilatada por envolvimento vascular 
Tabela 1 - Critérios diagnósticos do ACR com sensibilidade de 90,5\% e especificidade de 97,8\%

Idade $<40$ anos

Diminuição dos pulsos braquiais

Claudicação de extremidades

Diferença de $10 \mathrm{mmHg}$ na PA sistólica de MS

Sopros em subclávias e aorta

Alterações angiográficas de aorta e seus arcos principais

MS = membros superiores; $\mathrm{PA}=$ pressão arterial.

Adaptado de Hunder et al. ${ }^{30}$.

difuso do miocárdio, neurológico (síncope, cefaléia, acidente vascular), oftalmológico (retinopatia por hipoperfusão), formação de shunt arteriovenoso, insuficiência renal, e envolvimento dermatológico ${ }^{26}$, eritema nodoso, pioderma gangrenoso e fenômeno de Raynaud ${ }^{6,27,28}$.

No ambulatório da disciplina de Angiologia da Faculdade de Ciências Médicas (FCM), no Hospital Universitário Pedro Ernesto (HUPE), da Universidade do Estado do Rio de Janeiro (UERJ), são utilizados os critérios de classificação do American College of Rheumatology (ACR) para AT (Tabela 1) e a definição de AT proposta pela Conferência Internacional de Chapeel Hill ${ }^{29}$ como métodos auxiliares no diagnóstico. Os parâmetros de atividade propostos pelo National Institute of Health (NIH) são rotineiramente aplicados para aferir a atividade da doença. Falha do esquema terapêutico é considerada quando persistem os sinais clínicos de atividade, recidiva na redução terapêutica ou toxicidade inaceitável, presença de novas lesões ou até evolução do tipo angiológico avaliado pelo duplex scan e/ou arteriográfico $^{30}$.

A classificação das lesões à luz da angiografia revisada na Conferência Internacional de AT $^{29}$, em 1994, e publicada por $\mathrm{Hata}^{31}$ divide a doença em subtipos: tipo 1, que acomete ramos do arco aórtico; tipo 2a, aorta ascendente, arco aórtico e seus ramos; tipo 2b, idem ao anterior, com inclusão de aorta torácica; tipo 3, aorta torácica, aorta abdominal e/ou artérias renais; tipo 4, aorta abdominal e/ou artérias renais; tipo 5 , junção dos tipos $2 \mathrm{~b}$ e $4^{16,29,31}$.

Quanto ao tipo de lesão vascular, as lesões estenóticas e obstrutivas prevalecem, seguidas das dilatações aneurismáticas ${ }^{24}$. Destas, os aneurismas são os que têm incidência variável, maior no sudeste asiático e menor no continente americano ${ }^{24}$.

Os objetivos deste estudo foram: 1) descrever as alterações clínicas, laboratoriais e vasculares avaliadas em 36 pacientes acompanhados no período de 1977-2006; e 2) descrever as alterações na parede da carótida pelo duplex scan.

\section{Método}

Trinta e seis pacientes foram acompanhados na disciplina de Angiologia do HUPE, na UERJ, no período de 1977 a 2006. Informações demográficas, como cor, sexo e idade, e clínicas, como claudicação em MS e membro inferior (MI), hipertensão arterial, doença autoimune, tuberculose e vírus da imunodeficiência adquirida (HIV), tempo do diagnóstico e período de doença representado em anos, foram avaliadas.

A velocidade de hemossedimentação (VHS) mm/dL e a proteína $\mathrm{C}$ reativa (PCR) $\mathrm{mg} / \mathrm{dL}$ foram os marcadores empregados. $\mathrm{O}$ duplex scan analisou carótidas, renais, subclávias e aorta. A espessura da parede das artérias carótidas foi estratificada em quatro categorias: $\geq 3 \mathrm{~mm}$; $<3 \mathrm{e} \geq 1,7 \mathrm{~mm} ;<1,7 \mathrm{e} \geq 1,2 \mathrm{~mm}$; e $<1,2 \mathrm{~mm}$, utilizadas para avaliar a evolução da doença.

Glicocorticóides e imunossupressores, como a azatioprina (AZO), metotrexate e ciclofosfamida, ou associações foram utilizados. Tratamento cirúrgico e/ou endovascular foram procedimentos realizados (pontes, angioplastias com ou sem utilização de stents ou endopróteses). 
Tabela 2 - Variáveis clínicas, laboratoriais e tempo de doença decorrido do início dos sintomas ao diagnóstico

\begin{tabular}{lccc}
\hline Associações clínicas e laboratoriais & $\mathbf{n}$ & $\%$ & $\mathbf{p}$ \\
\hline Hipertensão & 31 & 86,1 & $<0,005$ \\
Claudicação de membros inferiores & 11 & 30,5 & \\
Claudicação de membros superiores & 25 & 69,5 & $<0,005$ \\
Doença auto-imune & 7 & 19,4 & \\
Tuberculose & 3 & 8,3 & \\
HIV & 1 & 2,7 & \\
Tempo entre início dos sintomas e diagnóstico (anos) & & & $<0,005$ \\
7,9 & 36 & 100 & $<0,005$ \\
3 & 20 & 55 & $<0,005$ \\
10 & 27 & 75 & $<0,005$ \\
VHS (mm) & 36 & 100 & \\
$>60$ & 18 & 50 & \\
$>26$ & 31 & 86,1 & \\
\hline
\end{tabular}

HIV = vírus da imunodeficiência adquirida; VHS = velocidade de hemossedimentação.

O banco de dados foi digitado e analisado pelos programas Epi-Info e Statistical Package for the Social Sciences (SPSS). O teste qui-quadrado analisou as variáveis, com significância de $\mathrm{p}<0,05$.

Este trabalho foi submetido e aprovado em 28 de fevereiro de 2008 pela Comissão de Ética em Pesquisa da FCM do HUPE da UERJ.

\section{Resultados}

A amostra compreendeu 36 pacientes -10 brancos, 35 mulheres, idade média de $31,7 \pm 13,7$, com prevalência significante na quarta década $(\mathrm{p}<0,005)$. Hipertensão arterial esteve presente em $85,2 \%$, e claudicação de MI e MS, em 30,5 e 69,5\%, respectivamente.

Doenças auto-imunes, tuberculose pulmonar e extrapulmonar e HIV correlacionaram-se com a AT nesta coorte em 19,4, 8,3 e 2,7\%, respectivamente.

O tempo decorrido entre o início dos sintomas e o diagnóstico foi de 7,9 anos, com evolução da doença de 3 anos em 55\% dos casos e de 10 anos em 75\%, até o diagnóstico.

A VHS foi considerada como marcador de fase aguda, com 50\% > $60 \mathrm{~mm}$ e os demais entre 26 e $28 \mathrm{~mm}$ $(\mathrm{p}<0,005)$ (Tabela 2). PCR mg/dL foi realizado em 18, variando 0,4-25 na admissão, para 0,11-1,9 na evolução.

O duplex scan foi realizado em $88 \%$ para avaliação de carótidas, subclávias, vertebrais e aorta.

Lesões na aorta foram detectadas em oito (22\%), sendo quatro oclusões, dois aneurismas infra-renais e um torácico. Outras artérias acometidas foram as renais e a subclávia (19\%), uma oclusão bilateral de carótidas e algum grau de estenose nos MI (25\%). Ao duplex scan, as artérias carótidas foram as mais acometidas, com $47,2 \%$.

A espessura da parede arterial foi realizada em $83 \%$ na artéria carótida comum, com os seguintes valores: $\geq$ $3 \mathrm{~mm},<3 \mathrm{e} \geq 1,7 \mathrm{~mm},<1,7 \mathrm{e} \geq 1,2 \mathrm{~mm}, \mathrm{e}<1,2 \mathrm{~mm}$ em $42,8,18,7,1$ e $32 \%$, respectivamente $(\mathrm{p}<0,005)$ (Tabela 3). As Figuras 1, 2 e 3 ilustram alterações vasculares: duplex scan com espessamento da íntima carotídea, antes e após tratamento imunossupressor, mostrando redução da espessura médio-intimal de 1,8 para $0,9 \mathrm{~mm}$; arteriografia com estenose supra-aórtica; e angio-RM com estenose da aorta abdominal, respectivamente.

Os glicocorticóides foram utilizados em $61 \%$, AZO em $16,6 \%$ e AZO com ciclofosfamida em $8,3 \%$. 
Tabela 3 - Artérias acometidas ao exame duplex scan e variação da espessura parietal (mm) da artéria carótida

\begin{tabular}{lccc}
\hline $\begin{array}{l}\text { Acometimento arterial: } \\
\text { espessura parietal (mm) }\end{array}$ & $\mathbf{n}$ & $\%$ & $\mathbf{p}$ \\
\hline Carótida & 17 & 47,2 & \\
$>3$ & 14 & 41,1 & $<0,005$ \\
$1,71-3$ & 6 & 18 & \\
$1,21-1,7$ & 3 & 8,8 & \\
$<1,21$ & 11 & 32,1 & \\
Aorta & 7 & 19,4 & \\
Subclávia & 5 & 13,8 & \\
Renal & 3 & 8,3 & \\
\hline
\end{tabular}

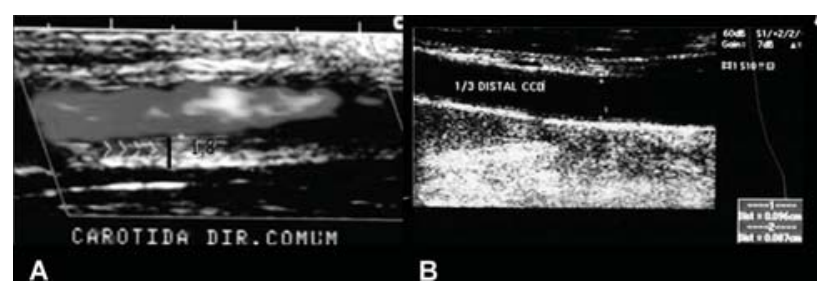

Figura 1 - A) Duplex scan para avaliação da espessura da íntima da carótida comum $(1,8 \mathrm{~mm})$; B) após tratamento $(0,9 \mathrm{~mm})$

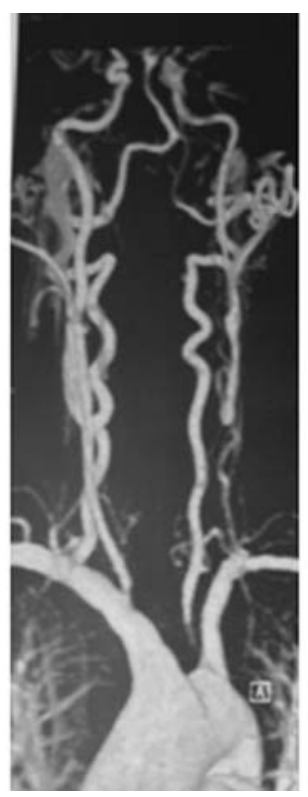

Figura 2 - Arteriografia, visualizando estenoses nas carótidas, vertebrais e artérias supra-aórticas

Procedimento cirúrgico ou endovascular foi realizado em $30,5 \%$, sendo $16 \%$ "pontes" e angioplastias, $5 \%$

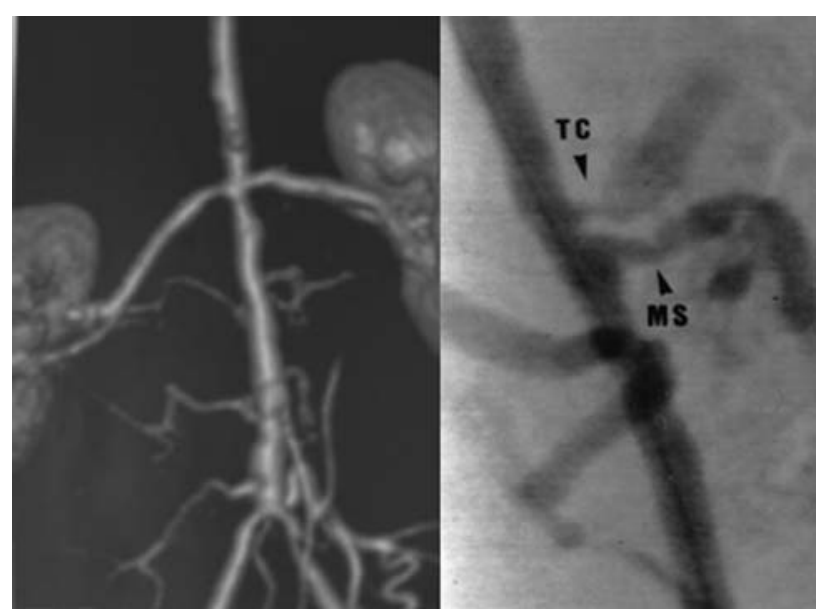

Angio- $\mathrm{RM}$ = angiorressonância magnética; $\mathrm{MS}$ = artéria mesentérica superior; $\mathrm{TC}=$ tronco celíaco.

Figura 3 - Angio-RM com alterações estenóticas na aorta abdominal e seus ramos, no tronco celíaco e na mesentérica superior

colocação de stents e endopróteses em 2\%, com dois óbitos por complicações cardiovasculares.

\section{Discussão}

A incidência em mulheres jovens até a quarta década é um consenso na literatura ${ }^{6-11,13-16}$, ressaltado por estudo chinês com 530 pacientes $^{17}$, onde $395(74,5 \%)$ eram mulheres. Na nossa casuística, esse percentual foi maior, ou seja, dos 36 pacientes, $97,2 \%$ eram mulheres.

Admite-se que elementos genéticos, agentes infecciosos e fatores auto-imunes estejam relacionados à evolução da $\mathrm{AT}^{5,33-35}$, realçando-se a possibilidade do 
Mycobacterium tuberculosis (MT) ${ }^{36-39}$, do estreptoco$\mathrm{co}^{40}$ e a discutível luética ${ }^{12}$. Nesta casuística, a correlação com agentes infecciosos ocorreu em 11,1\%, sem significância estatística.

A relação entre $\mathrm{AT}$ e $\mathrm{MT}^{39,41}$ é referida como a lesão granulomatosa, a reatividade cutânea à sua proteína purificada (PPD), freqüência variável com tuberculose ativa e o aspecto histológico da linfadenopatia, sugerindo infecção micobacteriana, apesar de os bacilos não terem sido encontrados nas lesões teciduais ${ }^{39,41}$. No presente estudo, 8,3\% apresentaram reatividade ao PPD, sendo dois associados à linfadenopatia e outro ao eritema nodoso. Foram submetidos à biópsia, comprovando-se MT, e um encontrava-se em quimioprofilaxia. Dois fatos devem ser avaliados: a possibilidade de infecção não-detectada e as reações auto-imunes pela micobactéria na $\mathrm{AT}^{37-41}$.

As manifestações clínicas são variáveis e dependentes da intensidade, local e velocidade do processo patológico. As lesões vasculares e a hipertensão arterial sistêmica (HAS) se desenvolvem em mais de 50\%, podendo ser consideradas essenciais, mesmo na ausência de lesões significativas. Segundo Sheikhzadeh et $\mathrm{al}^{42}$, a HAS foi reportada em $50-75 \%$, sendo conseqüência de alterações na complacência de artérias renais e aorta $^{42}$. Em nossa casuística, 31 (86,1\%) apresentaram HAS, possivelmente pelo acometimento das artérias renais.

O diagnóstico baseado na evolução clínica e exames laboratoriais, mais especificamente marcadores sorológicos de atividade de doença, são úteis. VHS e a PCR ultra-sensível, apesar de inespecíficos, são os mais utilizados. Para Salvarani et al. ${ }^{35}$, resultados normais na VHS não afastam a fase ativa da doença, sendo utilizada para evolução e terapêutica da AT.

A PCR ultra-sensível e a interleucina-6 têm se mostrado mais específicas para a AT. Biópsias associadas à VHS mostraram que $40 \%$ estavam com diagnósticos incorretos da fase de doença, pois alguns citados como em remissão estavam em atividade ${ }^{35}$.

Em nosso estudo, a VHS utilizada como marcador de atividade de doença foi estatisticamente significativa.
Diagnóstico por imagem apresenta resultados mais efetivos. Arteriografia era o exame considerado padrãoouro para o diagnóstico. $\mathrm{O}$ fato de ser invasivo traz informações exatas de lesão de parede e lúmen arterial. O duplex scan, na avaliação de atividade de doença, mostra-se específico. E, finalmente, a angio-RM para avaliação de grau de estenose da aorta, atualmente, é muito específica ${ }^{9,11}$.

A avaliação por duplex scan na fase inicial de doença, na presença de sintomas inespecíficos, mostrou-se efeti$\mathrm{va}^{8,43,44}$, ressaltando alterações parietais sem causar repercussão hemodinâmica com indicação e instituição precoce da terapêutica, controlando a evolução da AT.

Park et al ${ }^{45}$ classificaram a espessura média intimal da carótida comparando atividade $(2,5-5 \mathrm{~mm})$ e inatividade (1,1-2 mm): ressaltam o diâmetro do vaso $\geq 10 \mathrm{~mm}$ na atividade e $\leq 0,7 \mathrm{~mm}$ como fase inativa. Andrews \& Mason ${ }^{9}$, concordantes com esses parâmetros, excluíram placas ateroscleróticas não-homogêneas e calcificadas na parede do vaso. No presente estudo, estas alterações parietais mostraram-se mais evidentes, com graus variados de alterações hemodinâmicas.

O duplex scan seriado não mostrou correlação com a melhora instituída pelo tratamento, sugerindo-se ampliação dos estudos ${ }^{8}$.

Nesta casuística, o duplex scan foi utilizado em 34 $(94,4 \%)$, com acompanhamento anual, ressaltando-se que o aumento da espessura da parede arterial foi significativo.

A terapia para AT é baseada na corticoterapia. Quando necessário, associam-se outros imunossupressores, como metotrexate, AZO, ciclofosfamida, micofenolato mofetil e anti-TNF ${ }^{17,42,45-49}$.

Maksimowicz-McKinnon et al. ${ }^{48}$, em estudo prospectivo, referiram que $73 \%$ necessitaram associação com corticóide com doses inferiores a $10 \mathrm{mg}$, na seguinte ordem: metotrexate, AZO, micofenolato mofetil, ciclofosfamida e infliximabe (anti-TNF).

Drogas como o infliximabe necessitam de estudos mais amplos para avaliar sua eficácia, sendo, até o momento, seus resultados satisfatórios ${ }^{44-48}$. 
Hunder ${ }^{30}$ e Jennete et al. ${ }^{29}$, na Conferência do Consenso Internacional e no estudo do NIH, respectivamente, ressaltam os resultados de remissão com corticoterapia em associação com metotrexate satisfatórios em até $60 \%$. Poucos pacientes não atingiram remissão e necessitaram de anti-TNF ${ }^{46}$. Em nosso estudo, $22(61,1 \%)$ utilizaram corticoterapia em doses regressivas, e os demais, outros imunossupressores em associação, para manutenção da remissão.

Em trabalho retrospectivo ${ }^{15}$, foram referidos 513 casos de ressecção de aorta ascendente por aneurismas, e, destes, apenas 33 tiveram diagnóstico anatomopatológico de aneurismas de origem vasculítica. $\mathrm{O}$ aneurisma isolado de artéria renal é raro ${ }^{49}$.

Ressaltamos, em nosso estudo, as lesões estenóticas, seguidas das obstrutivas e três aneurismas (dois infrarenais e um pulmonar), além de um de subclávia esquerda associado ao de aorta ascendente. Conforme corroborado por outros estudos ${ }^{50,51}$, as lesões se apresentaram, em sua maior parte, como estenóticas e oclusivas.

Alguns pacientes não atingem remissão mesmo com o tratamento adequado, resultando evolução vascular progressiva, com indicação de procedimento cirúrgico. Os resultados com cirurgia convencional apresentaram maior tempo de perviedade do enxerto. O procedimento endovascular apresenta resultados melhores com as angioplastias, sem colocação de stents. Atualmente, stent farmacológico revestido de imunossupressor está sendo avaliado ${ }^{46}$.

Em 11 pacientes (30,5\%) deste estudo, foram realizados procedimentos cirúrgicos, como pontes convencionais, seguidos de angioplastias. Ressalta-se uma utilização de angioplastia e stent, que ocluiu 4 meses após, necessitando reintervenção. O estudo de Sato et al. ${ }^{44}$, em nosso meio, retrospectivo, com 30 pacientes, corrobora a indicação de procedimento cirúrgico em $30 \%$, apesar do tratamento clínico ${ }^{44}$.

$\mathrm{Na}$ nossa casuística, ocorreram dois $(5,5 \%)$ óbitos por complicações vasculares relacionadas à doença.

\section{Conclusões}

A VHS, a PCR e a avaliação da espessura da parede arterial pelo duplex scan foram importantes marcadores para o acompanhamento da doença. A observação de rotinas clínicas faz-se necessária para o diagnóstico da doença no menor tempo possível, reduzindo-se a morbimortalidade. Procedimentos cirúrgicos, quando realizados em fase de atividade da $\mathrm{AT}$, mostraram resultados negativos; no entanto, na fase inativa ou de remissão, obtiveram-se resultados satisfatórios.

\section{Referências}

1. Martorell F, Fabré J. El sindrome de obliteración de los troncos supra aórticos. Med Clin (Barc). 1944;2:26-30.

2. Heberer G, Rau G, Löhr HH. Enfermedades de la aorta y de las grandes artérias. Barcelona: Científico-Médica; 1970.

3. Vidal-Barraquer F. Patologia vascular: fisiopatologia, clínica e tratamiento. Barcelona: Científico-Médica; 1973.

4. Cossermelli W, org. Vasculites. São Paulo: Fundação para o Desenvolvimento da Reumatologia; 2002.

5. Borelli FAO, Passareli Jr. O, Souza MG, Fagundes Jr. AAP, Pimenta E, Amoseo C. Arterite de Takayasu: conhecer para diagnosticar. J Bras Nefrol. 2005;27(4):215-9.

6. Kerr GS. Takayasu's arteritis. Rheum Dis Clin North Am. 1995;21:1041-58.

7. Seko Y. Takayasu's arteritis: insights into immunopathology. Jpn Heart J. 2000;41:15-26.

8. Sun Y, Yip PK, Jeng JS, Hwang BS, Lin WH. Ultrasonographic study and long term follow up of Takayasu's arteritis. Stroke. 1996;27:2178-82.

9. Andrews J, Mason JC. Takayasu's arteritis: recent advances in imaging offer promise. Rheumatology (Oxford). 2007;46:615 .

10. Mayo J, Culham JA. Magnetic resonance imaging in pediatric vascular disease. Can Assoc Radiol J. 1987;38:165-9.

11. Baptista LPS. Contribuição da ressonância magnética na arterite de Takayasu [tese]. São Paulo: Universidade de São Paulo; 2006.

12. Heggtveit HA. Syphilitic aortitis, a clinipathologic autopsy study of 100 cases. Circulation. 1964;29:346-55.

13. Ishikawa K. Natural history and classification of occlusive thromboarthropathy. Circulation. 1978;57:27-55.

14. Watts RA, Carruthers DM, Scott DG. Epidemiology of systemic vasculitis: changing incidence or definition. Semin Arthritis Rheum. 1995;25:28-34.

15. Homme JL, Aubry MC, Edwards WD, et al. Surgical pathology of the ascending aorta: a clinicopathologic study of 513 cases. Am J Surg Pathol. 2006;30:1159-68.

16. Moriwaki R, Noda M, Yajima M, Sharma BK, Numano F. Clinical manifestations of Takayasu arteritis in India and Japan: new classification of angiographic findings. Angiology. 1997;48:369-79. 
17. Zheng D, Fan D, Liu L. Takayasu arteritis in China: a report of 530 cases. Heart Vessels Suppl. 1992;7:32-6.

18. Kinare SG. Aortitis in early life in India and its association with tuberculosis. J Pathol. 1970;100:69-76.

19. Numano F. Differences in clinical presentation and outcome in different countries for Takayasu's arteritis. Curr Opin Rheumatol. 1997;9:12-5.

20. Numano F, Okawara M, Inomata H, Kobayashi Y. Takayasu's arteritis. Lancet. 2000;356:1023-5.

21. Chauhan SK, Tripathy NK, Nityanand S. Antigenic targets and pathogenicity of anti-aortic endothelial cell antibodies in Takayasu arteritis. Arthritis Rheum. 2006;54:2326-33.

22. Verma DK, Tripathy NK, Verma NS, Tiwari S. Interleukin 12 in Takayasu's arteritis: plasma concentrations and relationship with disease activity. J Rheumatol. 2005;32:2361-3.

23. Tripathy NK, Gupta PC, Nityanand S. High TNF-alpha and low IL-2 producing $T$ cells characterize active disease in Takayasu's arteritis. Clin Immunol. 2006;118:154-8.

24. Numano F, Kobayashi S. Takayasu arteritis: beyond pulselessness. Intern Med. 1999;38:226-32.

25. Rodriguez-Pla A, Stone JH. Vasculitis and systemic infections. Curr Opin Rheumatol. 2006;18:39-47.

26. Perniciaro CV, Winkelmann RK, Hunder GG. Cutaneous manifestations of Takayasu's arteritis. J Am Acad Dermatol. 1987; 17:998-1005.

27. Hall S, Barr W, Lie JT, Stanson AW, Kazmier FJ, Hunder GG. Takayasu arteritis. A study of 32 north american patients. Medicine (Baltimore). 1985;64:89-99.

28. Hall S, Buchbinder R. Takayasu's arteritis. Rheum Dis Clin North Am. 1990;16:411-22.

29. Jennette JC, Falk RJ, Andrassy K, et al. Nomenclature of systemic vasculitis: proposal of an international consensus conference. Arthritis Rheum. 1994;37:187-92.

30. Hunder GG, Arend WP, Bloch DA, et al. The American College of Rheumatology 1990 criteria for the classification of Takayasu's arteritis. Arthritis Rheum. 1990;33:1129-34.

31. Hata A, Numano F. Magnetic resonance imaging of vascular changes in Takayasu's arteritis. Int J Cardiol. 1995;52:31-7.

32. Hoffman GS. Takayasu arteritis: lessons from the American National Institutes of Health experience. Int J Cardiol. 1996;54 Suppl:S99-102.

33. Sano K, Aiba T. Pulseless disease: summary of our 62 cases. Jpn Circ J. 1966;30:63-7.

34. Sato EI, Sassaki Jr RH, Leão CS, Hatta FS, Nunes DS, Santo BE. Clinical and angiographic features of Takayasu's arteritis. Rev Bras Reumatol. 1998;38:9-14.

35. Salvarani C, Cantini F, Boiardi L, Hunder GG. Laboratory investigations useful in giant cell arteritis and Takayasu arteritis. Clin Exp Rheumatol. 2003;21:S23-8.

36. Kinare SG. Aortitis in early life in India and its association with tuberculosis. J Pathol. 1970;100(1):69-76.

37. Pantell RH, Goodman BW. Takayasu's arteritis: the relationship with tuberculosis. Pediatrics. 1981;67:84-8.
38. Shoenfeld Y, Isenberg DA. Mycobacteria and autoimmunity. Immunol Today. 1998;9:178-82.

39. Moraes MF, Ordway D, Oliveira L, et al. Cellular immune responses to mycobacterium tuberculosis in a patient with Takayasu's arteritis. Rev Port Cardiol. 1999;18:359-67.

40. Cupps TR, Fauci AS. Takayasu's arteritis. In: Cupps TR, Fauci AS. The vasculitis. Major problems in internal medicine. Philadelphia: WB Saunders; 1981, p. 107-12. (vol. VXXI, The vasculitis.)

41. Morrison RCA, Milner LS, Jacobs D, Thomson PD, Franklin J, Ninin D. The role of mycobacteria in Takayasu's arteritis [abstract]. Kidney Int. 1989;35:973.

42. Sheikhzadeh A, Tettenborn I, Noohi F, Eftekharzadeh M, Schnabel A. Occlusive thromboaortopathy (Takayasu disease): clinical and angiographic features and a brief review of literature. Angiology. 2002;53:29-40.

43. Schmidt WA, Nerenheim A, Seipelt E, Poehls C, GromnicaIhle E. Diagnosis of early Takayasu arteritis with sonography. Rheumatology (Oxford). 2002;41:496-502.

44. Sato EI, Lima DN, Espírito Santo B, Hata F. Takayasu arteritis: treatment and prognosis in a university center in Brazil. Int J Cardiol. 2000;75:S163-6.

45. Park SH, Chung JW, Lee JW, Han MH, Park JH. Carotid artery involvement in Takayasu's arteritis evaluation of the activity by ultrasonography. $\mathrm{J}$ Ultrasound Med. 2001;20:371-8.

46. Liang P, Hoffman GS. Advances in the medical and surgical treatment of Takayasu arteritis. Curr Opin Rheumatol. 2005;17(1):16-24.

47. Souza AWS, Neves RMS, Oliveira KR, Sato EI. Tratamento da arterite de Takayasu. Rev Bras Reumatol. 2006;46:2-7.

48. Maksimowicz-Mckinnon K, Clark T, Hoffman G. Limitations of therapy and a guarded prognosis in an American cohort of Takayasu arteritis patients. Arthritis Rheum. 2007;56:1000-9.

49. Matsubara K, Matsumoto K, Kameyama K, Obara H, Kitajima M. Large renal artery aneurysm in Takayasu arteritis. J Vasc Surg. 2006;44:1107-9.

50. Robinson WP 3rd, Detterbeck FC, Hendren RL, Keagy BA. Fulminant development of mega aorta due to Takayasu arteritis: a case report and review of the literature. Vascular. 2005;13:178-83.

51. Regina G, Bortone A, Impedovo G, De Cillis E, Angiletta D, Marotta V. Endovascular repair of thoracic stent graft bulging rupture in a patient with multiple thoracic aneurysms due to Takayasu Arteritis disease. J Vasc Surg. 2007;45:391-4.

Correspondência:

Marília Duarte Brandão Panico

Tel.: (21) 2208.6030, (21) 2587.6624, (21) 9621-4207

E-mail:mariliapanico@hotmail.com, mariliapanico@uol.com.br 